\section{Dmitry Mikhalchenko ${ }^{\square}\left(\mathbb{D}\right.$, Alexander Vorobyev $^{2}$ (D), Alexander Alexandrov² (1D, Yuliya Makedonova ${ }^{3}$ (D), Vladimir Shkarin ${ }^{4}$ (D)}

\author{
${ }^{1}$ Department of Propaedeutics of Dental Diseases; \\ ${ }^{2}$ Department of Operative Surgery and Topographic Anatomy; \\ ${ }^{3}$ Dentistry Institute; \\ ${ }^{4}$ Department of Public Health and Health Care of Postgraduate Faculty; \\ Volgograd State Medical University, Volgograd, Russia
}

\section{dvmihalchenko@volgmed.ru}

motional disorders resulting from stress cause chronic long lasting inflammatory diseases including diseases of the oral cavity [11]. Complications following dental implantation that manifests in inflammation of the periimplant tissue is not an exception. Patients are not able either eat normally or speak and all this affects their life. In this case psycho-physiological condition of these patients also changes. Early discovery of the stress factor and later the development of psychoemotional disorders is one of the important purposes of a dentist as it prevents development of complications during dental treatment.

At present, numerous methods exist to determine a person's psychoemotional condition. These are mainly various questionnaires that patients fill. In the era of modern technologies a software on Android platform examines microhemodynamics and determines the degree of stress: low, medium or high one within a few seconds. Though, more objectively, stress diagnostics can be carried out with laser doppler flowmetry by studying a few parameters. The method makes it possible to promptly and noninvasively reveal specific numerical indices by calculating the oscillation spectrum of different origin, essentially by increasing or decreasing the amplitudes of endothelial, myogenous and neurogenous oscillation [12].

To investigate changes in the microdynamics of the oral mucosa under psychoemotional stress using the data acquired with laser Doppler flowmetry.

\section{MATERIAL AND METHODS}

30 volunteers with inflammation of the periimplant tissue of the oral mucosa participated in the study. The study was approved by the Regional Committee of Ethics, Protocol No 2115/1-2019 of April 19, 2019. Prior to LDF-metry, all patients with mucositis were given questionnaires that were analyzed using the method of psychological stress measure PSM-25. The results were interpreted and the data processed by calculating the total amount of points after answering all the questions. 125 points and higher showed a high level of stress, 100-125 points - a medium level and less than 99 points - a low level of stress.

Laser doppler flowmetry was performed while the numerous diseases including dental ones. Psychoe- 
patient was sitting on the dental chair. The sensor was placed on the inflamed periimplant area to study hemodynamics of the oral mucosa. Capillary blood flow was monitored for 10 minutes. At the first stage the indicator of microcirculation, the root-mean-square deviation and coefficient of variation were estimated and at the second stage the contribution and oscillation of high and low frequency flux motions were studied.

\section{RESULTS}

Based on the data obtained from the questionnaires, it can be said that all the patients were in a stress situation. So, 12 patients (40\%) showed 130 points, 10 patients had 160 points (33,3\%), 5 patients -180 points $(16,7 \%)$ and 3 patients showed 195 points (10\%). The average amount of points were $154,8 \pm 4,2$ that was the evidence of a high level of stress.

To obtain normalized indices of LDF-gram, while carrying out LDF-metry, there was a control group of normal people who did not suffer from stress. The absence of a psychoemotional factor was also confirmed by questioning. The patients under stress conditions showed blood vessels dilatation against lower activity of the sympathetic vasomotors and decreased tone of precapillaries, increased amplitude of endothelial, neurogenous and myogenous oscillations. So, increased amplitude of endothelial oscillations (VLF by $57 \%$, $\mathrm{p}<0,05)$ characterizes a higher activity of endothelial secretory function, development of endotheliumdependent dilatation of the vessels. Increased number of flux motions of the myogenous origin (LFM by 64\%, $\mathrm{p}<0,05)$ characterizes a lower tone of precapillaries, Increased amplitude of neurogenous oscillations $(\mathrm{LFH}$ by $54 \%, p<0,05)$ is the evidence of a lower activity of sympathetic adrenergic vasomotors and development of sympathetic vasodilatation. Increased oscillations of the pulse and respiratory waves occur against pulse acceleration and respiratory impact on the vegetative heart nerves alongside with the inflow of arterial blood and difficulty in venous outflow. The study of the non-oscillatory indices showed the increase of the microcirculation index $\mathrm{M}$ by $37 \%$, but the root-meansquare deviation and variation index are 35\% lower and makes $5,32 \pm 0,3 \%$. Lowered speed of the local blood flow is associated both with weakened active factors of blood flow regulation and decreased flux motions energy.

\section{DISCUSSION}

Thus, the analysis of the data obtained is the evidence of expressed microcirculatory changes in a stress situation. Laser doppler flowmetry is a noninvasive method of examination that shows objectively the state of microhemodynamics and can be used as a diagnostic method of psychoemotional condition at dental treatment.

\section{CONCLUSION}

Investigation of microcirculation parameters in patients with dental implant complications has revealed disturbances of microhemodynamics. Therefore, further studies may help find the cause/effect relationships that justifies the need for such studies in the future.

\section{REFERENCES}

1. ShKarin V.V., Grinin V.M., Khalfin R.A., DMitrienko S.V., DomenYuk D.A. Specific features of grinder teeth rotation at physiological occlusion of various gnathic dental arches // Archiv EuroMedica. 2019. Vol. 9; 2: 168-173. https://doi. org/10.35630/2199-885X/2019/9/2/168

2. ShKarin V.V., IVANov S.Yu., DMitrienko S.V., DomenYuK D.A., LePILIN A.V., DomenYuK S.D. Morphological specifics of craniofacial complex in people with varioustypes of facial skeleton growth in case of transversal occlusion anomalie // Archiv EuroMedica. 2019. Vol. 9; 2: 5-16. https://doi. org/10.35630/2199-885X/2019/9/2/5

3. ShKarin V.V., Grinin V.M., Khalfin R.A., DMitrienko S.V., Domenyuk D.A. Specific features of transversal and vertical parameters in lower molars crowns at various dental types of arches // Archiv EuroMedica. 2019. Vol. 9; 2: 174-181. https:// doi.org/10.35630/2199-885X/2019/9/2/174

4. Domenyuk D.A., Shkarin V.V., Porfiriadis M.P., DMitrienko D.S., DMitrienko S.V. Classification of facial types in view of gnathology // Archiv EuroMedica, 2017. Vol. 7; 1. P. 8-13.

5. Borodina V.V., Domenyuk D.A., WeISHeim L.D., DMitrienko S.V. Biometry of permanent occlusion dental arches - comparison algorithm for real and design indicators // Archiv EuroMedica. 2018. Vol. 8 (1). P. 25-26. https://doi.org/10.35630/2199$885 \mathrm{X} / 2018 / 8 / 1 / 25$

6. Domenyuk D.A., ShKarin V.V., Porfiriadis M.P., DMitrienko D.S., DMitrienko S.V. Algorithm for forecasting the shape and size of dent arches front part in case of their deformations and anomalies //Archiv EuroMedica, 2017. Vol.7; 2. P. 105-110.

7. Domenyuk D.A., Vedeshina E G., Dmitrienko S.V. Correlation of dental arch major linear parameters and odontometric indices given physiological occlusion of permanent teeth in various face types // Archiv EuroMedica. 2016. Vol. 6; 2. P. 18-22.

8. Domenyuk D.A., Vedeshina E G., Dmitrienko S.V. Mistakes in Pont (Linder-Hart) method used for diagnosing abnormal dental arches in transversal plane // Archiv EuroMedica. 2016. Vol. 6 (2). P. 23-26.

9. DMitrienko S.V., Domenyuk D.A., Vedeshina E.G. Shape individualization in lower dental arches 
drawn on basic morphometric features // Archiv EuroMedica, 2015 Vol. 5; 1. P. 11.

10. ShKarin V.V, Davydov B.N., DomenYuk D.A, DMITRIENKo S.V. Non-removable arch orthodontic appliances for treating children with congenital maxillofacial pathologies - efficiency evolution // Archiv EuroMedica, 2018. Vol. 8; 1. P. 97-98. https://doi. org/10.35630/2199-885X/2018/8/1/97
11. Mikhalchenko D.V., Makedonova Yu.A., PoROYSKY S.V. Stress as a factor predictor of perimplantitis development (review) // Georgian medical news, 2019. Vol. 9 (294) P. 46-50.

12. Zizzi A, Aspriello SD, Rubini C, Goteri G.

Peri-implant diseases and host inflammatory response involving mast cells: a review.// Int J Immunopathol Pharmacol. 2011. Vol. 24; 3. P. 557-566. 